\title{
Lung volume reduction in emphysema: a pragmatic prospective cohort study
}

\author{
Christophe Dooms ${ }^{1,6}$, Astrid Blondeel ${ }^{2,6}$, Laurens J. Ceulemans ${ }^{3}$, \\ Johan Coolen ${ }^{4}$, Stephanie Everaerts (1)', Heleen Demeyer ${ }^{2,5}$, Thierry Troosters ${ }^{2}$, \\ Geert Verleden ${ }^{1}$, Dirk Van Raemdonck ${ }^{3}$ and Wim Janssens (ib) ${ }^{1}$
}

Affiliations: ${ }^{1}$ Clinical Dept of Respiratory Diseases, University Hospitals Leuven, BREATHE, Dept CHROMETA, KU Leuven, Leuven, Belgium. ${ }^{2}$ Dept of Rehabilitation Sciences, KU Leuven, Leuven, Belgium. ${ }^{3}$ Clinical Dept of Thoracic Surgery, University Hospitals Leuven, BREATHE, Dept CHROMETA, KU Leuven, Leuven, Belgium. ${ }^{4}$ Clinical Dept of Radiology, University Hospitals Leuven, Leuven, Belgium. ${ }^{5}$ Dept of Rehabilitation Sciences, Ghent University, Leuven, Belgium. ${ }^{6}$ These authors contributed equally.

Correspondence: Christophe A. Dooms, Herestraat 49, 3000 Leuven, Belgium.

E-mail: christophe.dooms@uzleuven.be

ABSTRACT Limited guidance exists for the implementation of lung volume reduction interventions in routine clinical care. We designed a pragmatic study to evaluate a strategy including endoscopic lung volume reduction (ELVR) and lung volume reduction surgery (LVRS) in heterogeneous emphysema.

This prospective monocentre cohort study evaluated ELVR versus no-ELVR, followed by a cohort study evaluating LVRS. Primary outcome was the proportion of subjects with a forced expiratory volume in $1 \mathrm{~s}$ $\left(\mathrm{FEV}_{1}\right)$ improvement of $\geqslant 100 \mathrm{~mL}$ at 3 -month follow-up. Changes in $\mathrm{FEV}_{1}$, residual volume (RV), 6-min walk distance (6MWD) and quality of life (St George's Respiratory Questionnaire (SGRQ)) were evaluated at 6-month follow-up. Hospital stay and treatment-related serious adverse events were monitored.

From 106 subjects screened, 38 subjects were enrolled comparing ELVR $(n=20)$ with no-ELVR $(n=18)$. After 6 months' follow-up, eligible patients were referred for LVRS $(n=16)$ with another 6-month follow-up. At 3-month follow-up, 70\% of ELVR compared to $11 \%$ of no-ELVR $(\mathrm{p}<0.001)$ and $69 \%$ of LVRS had an $\mathrm{FEV}_{1}$ improvement of $\geqslant 100 \mathrm{~mL}$. Between-group differences (mean \pm SEM) for ELVR versus no-ELVR at 6month follow-up were $\mathrm{FEV}_{1}+0.21 \pm 0.05 \mathrm{~L}$; RV $-0.95 \pm 0.21 \mathrm{~L} ; 6 \mathrm{MWD} 58 \pm 17 \mathrm{~m}$ and SGRQ $-18 \pm 5$ points. At 6-month follow-up, within-group differences (mean \pm SEM) for LVRS showed $\mathrm{FEV}_{1}+0.27 \pm 0.06 \mathrm{~L}$; RV $-1.49 \pm 0.22 \mathrm{~L}$ and $6 \mathrm{MWD}+75 \pm 18 \mathrm{~m}$. Serious adverse events in $81 \%$ versus $45 \%$ of subjects $(\mathrm{p}=0.04)$ and a median hospital stay of 15 versus 5 days $(\mathrm{p}<0.001)$ were observed for LVRS versus ELVR, respectively.

This pragmatic prospective cohort study supports a clinical approach with ELVR as a less invasive first option and LVRS as powerful alternative in severe heterogeneous emphysema.

@ERSpublications

This pragmatic, real-life clinical algorithm evaluates an approach with endoscopic lung volume reduction as a less invasive first option and lung volume reduction surgery as a powerful alternative in advanced heterogeneous emphysema https://bit.ly/39gckqc

Cite this article as: Dooms C, Blondeel A, Ceulemans LJ, et al. Lung volume reduction in emphysema: a pragmatic prospective cohort study. ERJ Open Res 2021; 7: 00877-2020 [https:// doi.org/10.1183/23120541.00877-2020].

This article has been revised according to the erratum published in ERJ Open Res 2021; 7: 50877-2020 [https://oi.org/ $10.1183 / 23120541.50877-2020]$.

Editorial comment in ERJ Open Res 2021; 7: 00258-2021 [https://doi.org/10.1183/23120541.00258-2021].

This article has supplementary material available from openres.ersjournals.com

This study is registered at www.clinicaltrials.gov with identifier number NCT03264768. Data will be available upon reasonable request to the corresponding author.

Received: 24 Nov 2020 | Accepted after revision: 19 March 2021 | First published: 31 May 2021

Copyright $\odot$ The authors 2021. This version is distributed under the terms of the Creative Commons Attribution NonCommercial Licence 4.0. For commercial reproduction rights and permissions contact permissions@ersnet.org 


\section{Introduction}

The emphysema phenotype of COPD is associated with significant morbidity and mortality [1]. The standard of care consists of smoking cessation, inhaled long-acting bronchodilation, optimal nutrition and pulmonary rehabilitation to obtain symptom control, improvement in quality of life and reduction of further risks $[1,2]$. Despite these treatment strategies, patients with advanced emphysema can remain severely symptomatic. Lung volume reduction surgery (LVRS) and endoscopic lung volume reduction (ELVR) using one-way endobronchial valves (EBVs) have shown to improve dyspnoea, pulmonary function tests, quality of life and exercise capacity in a subset of these patients [3-10]. Controversy exists on the preferred method for lung volume reduction (LVR), as there is no clinical trial evidence on superiority of any of the LVR techniques. To our knowledge, limited guidance is available for the implementation of LVR interventions in routine clinical care [11-15].

Therefore, we performed a prospective cohort study to evaluate the benefit and safety of LVR in a high-volume emphysema expert centre. Our pragmatic study is not designed to demonstrate efficacy between LVRS and ELVR, but aims to inform on a treatment strategy for a target patient group and to provide evidence for its adoption into routine real-life clinical practice.

\section{Patients and methods}

Study design and participants

A single-centre pragmatic prospective trial design was used combining ELVR versus no-ELVR cohort study and a LVRS cohort study (figure 1). The study enrolled subjects between July 2017 and November 2018.

Eligible ambulatory emphysema patients had to meet inclusion criteria for a LVR intervention: presence of heterogeneous emphysema on computed tomography (CT) scan; forced expiratory volume in $1 \mathrm{~s}\left(\mathrm{FEV}_{1}\right)$ $<60 \%$ predicted, residual volume (RV) $>150 \%$ pred, total lung capacity (TLC) $>90 \%$ pred, RV/TLC ratio $\geqslant 0.55$; 6-min walk distance $(6 \mathrm{MWD})<450 \mathrm{~m}$; modified Medical Research Council dyspnoea score $\geqslant 2$; smoking cessation (confirmed by urinary cotinine test) for $\geqslant 6$ months; long-acting $\beta$-agonist/long-acting muscarinic antagonist bronchodilator therapy as a minimum therapy. For safety reasons, patients who met the following criteria were excluded: diffusing capacity of the lung or $\mathrm{FEV}_{1}<20 \%$ pred, $6 \mathrm{MWD}<100 \mathrm{~m}$, peak pulmonary artery systolic pressure $>50 \mathrm{mmHg}$ on echocardiography, left ventricular ejection fraction $<40 \%$ on echocardiography, body mass index (BMI), airflow obstruction, dyspnoea, exercise capacity (BODE) index $\geqslant 7$ and eligible for lung transplantation, arterial oxygen tension $<45 \mathrm{mmHg}$ or arterial carbon dioxide tension $>60 \mathrm{mmHg}$ at ambient air, and any previous thoracic surgery.

The study was approved by the ethical committee UZ/KU Leuven (Eudract number 2017-001323-47; study ID s60207). All participants provided written informed consent. The trial has been registered with www. clinicaltrials.gov (NCT03264768).

\section{Multidisciplinary emphysema expert meeting}

A multidisciplinary team including pulmonologists experienced in COPD and lung transplantation, chest radiologist, thoracic surgeon and interventional pulmonologist has been installed at our institution since the launch of the ELVR programme in June 2017.

A dedicated chest radiologist discussed unexpected findings on CT scan and provided a visual assessment of the type and distribution of emphysema and an estimation of fissure integrity. The syngo.via Pulmo3D software package (version 10; Siemens Healthcare, Erlangen, Germany) was used for quantitative CT measurements of emphysema destruction (emphysema destruction score expressed as the proportion of pixels below threshold density of $-910 \mathrm{HU}$ ). Target lobe selection was based on lobar emphysema quantification and emphysema heterogeneity on CT (absolute difference of $\geqslant 10 \%$ in destruction scores between the target and ipsilateral lobes). The decision making of this multidisciplinary emphysema expert meeting (MEET) finally addressed the target area for volume reduction in the context of individual morbidity risk and benefit.

After the MEET, eligible patients were invited for informed consent procedure, followed by baseline post-bronchodilator spirometry, lung volumes by plethysmography and diffusing capacity, baseline St George's Respiratory Questionnaire (SGRQ) and baseline exercise capacity measured by best out of two 6-min walk tests. In addition, a standardised high-resolution 1-mm noncontrast volumetric chest CT scan was sent for StratX Lung Analysis Platform assessment (a cloud-based CT analysis service). Patients with $\geqslant 80 \%$ fissure integrity by StratX were considered for a subsequent Chartis pulmonary assessment.

\section{Outcome measures}

The primary outcome measure was the proportion of subjects in the ELVR group who had an improvement in post-bronchodilator $\mathrm{FEV}_{1}$ of $\geqslant 100 \mathrm{~mL}$ compared to the proportion of subjects achieving this improvement in the no-ELVR group at 3-month follow-up. 


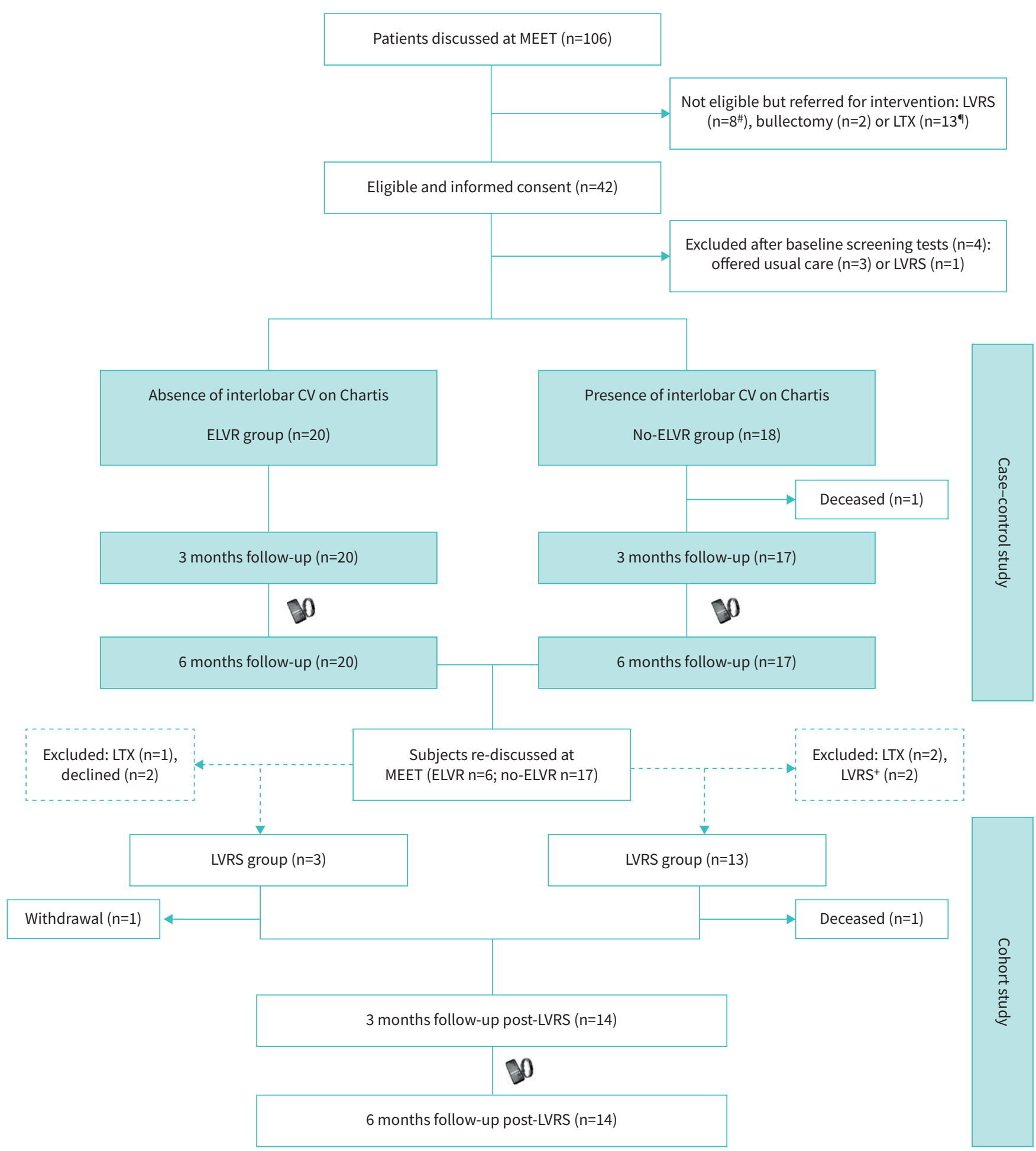

FIGURE 1 Consolidated Standards of Reporting Trials diagram of subject flow through the pragmatic trial. MEET: multidisciplinary emphysema expert meeting; LVRS: lung volume reduction surgery; LTX: lung transplantation; CV: collateral ventilation; ELVR: endoscopic lung volume reduction. " : not eligible due to 6 -min walk distance $>450 \mathrm{~m}$, fissure integrity on computed tomography scan $<70 \%$, intralobar heterogeneous emphysema; ": not eligible due to forced expiratory volume in $1 \mathrm{~s}<20 \%$, body mass index, airflow obstruction, dyspnoea, exercise capacity (BODE) index score $\geqslant 7$ and homogeneous emphysema; ${ }^{+}$: subjects did not consent to per-protocol follow-up.

The key secondary outcome measures comparing ELVR and no-ELVR groups included the absolute changes from baseline to 3- and 6-month follow-up for $\mathrm{FEV}_{1}, \mathrm{RV}$, functional residual capacity, TLC, $6 \mathrm{MWD}$, SGRQ total score and BODE index score. Furthermore, the response rates, based on established minimal clinical important difference (MCID) for $\mathrm{FEV}_{1}, \mathrm{RV}, 6 \mathrm{MWD}$ and SGRQ total score were analysed 
at 3- and 6-month follow-up [16-20]. An additional exploratory analysis reported the effect of LVRS on the primary and key secondary outcome measures at 6-month follow-up. The end-points evaluated in this study were well standardised and measured in a consistent manner. In-hospital stay and safety during the study period through 6-month follow-up were assessed through review of all adverse events reported at all scheduled or unscheduled visits. Adverse events were defined as any undesirable experience occurring to a subject during the study period and reported spontaneously or observed by the study staff. Serious adverse events were defined as any untoward medical occurrence that results in death, is life threatening, requires hospitalisation or prolongation of existing hospitalisation or results in persistent or significant disability.

\section{Statistical analysis}

The sample size calculation was based on the objective to obtain a proportion of $\geqslant 60 \%$ responders for a $\geqslant 100 \mathrm{~mL}$ improvement in post-bronchodilator $\mathrm{FEV}_{1}$ in the ELVR group compared to maximal $15 \%$ responders in the no-ELVR group at 3-month follow-up. As such, a sample size of 15 subjects in each arm was required for a power of $80 \%$ at the $0.05 \alpha$-level of significance. Given the possibility of valve removal before 3 months in the ELVR group, a pragmatic sample size of 20 in the treatment arm was accepted. All statistical analyses were performed using SAS version 9.4 (SAS Institute, Cary, NC, USA). Descriptive statistics included means \pm SD/SEM or median and range. A two-sample t-test, a Wilcoxon rank-sum test and a Fisher's exact test were performed to test for differences between groups at baseline. Absolute between-group changes from baseline were analysed using mixed-model analysis, retrieving interaction effect of visit $x$ intervention. Within-group differences were analysed by mixed-model time effects (visit as class variable). The response rates, based on established MCID, were compared by Fisher's exact test. Adverse events and hospital stay were evaluated by respectively Fisher's exact test and Wilcoxon rank-sum test. All subjects were included in the analysis to evaluate intention-to-treat (ITT). All patients were invited to come back for the final assessments. No imputation was performed in case of missing values.

\section{Results}

This study was conducted between July 2017 and January 2020. 106 patients were screened at the MEET, with 42 subjects meeting the eligibility criteria and consenting. After baseline screening tests, 38 subjects entered the trial (figure 1). Of these subjects, 18 had collateral ventilation and were allocated to the no-ELVR group, while 20 subjects were negative for collateral ventilation by Chartis assessment and were treated by EBVs (ELVR group). Baseline demographics and clinical characteristics were overall similar in both groups, except for TLC (table 1). After 6 months' follow-up, nonresponding ELVR subjects ( $\mathrm{n}=6)$ and subjects from the no-ELVR group $(n=17)$ were re-discussed at the MEET. Six ELVR subjects were considered for a surgical intervention: three subjects agreed to LVRS and consented further study follow-up; one subject declined LVRS; one subject was referred for lung transplantation; and one subject had undergone a wedge resection for a valve-related symptomatic pneumothorax deferring further surgical intervention. 17 no-ELVR subjects were considered for a surgical intervention: 13 subjects agreed per-protocol LVRS and follow-up; two subjects underwent LVRS without consent for further per-protocol follow-up; and two subjects were referred for lung transplantation. Finally, 16 subjects gave consent for per-protocol LVRS and a further 6-month follow-up (figure 1).

\section{Treatment details}

During ELVR a median of four endobronchial valves (range 3-6) per subject was implanted (15\% left lower, 50\% left upper lobe, 5\% right lower lobe, 15\% right upper lobe and 15\% right upper and middle lobe). A follow-up bronchoscopy was performed in seven (35\%) patients, of which one was for permanent removal of valves because of pneumothorax on day 2 requiring surgical repair, and six were to attempt restoration of valve function in the absence of lobar occlusion at 1-month follow-up CT scan. The median in-hospital stay for ELVR intervention was 5 days (range 5-55 days) (table 2). Reason for a prolonged (>10 days) in-hospital stay was pneumothorax $(n=2)$. During LVRS, all subjects underwent a bilateral lung volume reduction as decided by the MEET discussion. The median in-hospital stay for LVRS intervention was 14.5 days (range 7-61 days) (table 2). Four (25\%) patients were discharged with a Heimlich valve due to a persistent air leak.

\section{Primary outcome}

The results of the primary end-point are shown in figure 2. After 3 months, 70\% of the ELVR subjects compared with $11 \%$ of the no-ELVR subjects had a $\geqslant 100 \mathrm{~mL}$ improvement over baseline in $\mathrm{FEV}_{1}$ in the ITT population $(\mathrm{p}<0.01)$. Moreover, $69 \%$ of the LVRS subjects had $\mathrm{a} \geqslant 100 \mathrm{~mL}$ improvement over baseline in $\mathrm{FEV}_{1}$ at 3-month follow-up. 
TABLE 1 Baseline demographics and clinical characteristics for the endoscopic lung volume reduction (ELVR) group and the no-ELVR group

\begin{tabular}{|c|c|c|c|}
\hline & ELVR group & No-ELVR group & p-value \\
\hline Subjects $\mathrm{n}$ & 20 & 18 & \\
\hline Age years & $65 \pm 6$ & $63 \pm 5$ & 0.18 \\
\hline Female & 45 & 67 & 0.21 กาा \\
\hline BMI $\mathrm{kg} \cdot \mathrm{m}^{-2}$ & $23 \pm 3$ & $22 \pm 4$ & 0.43 \\
\hline Emphysema score at $-910 \mathrm{HU}^{\#}$ & $71 \pm 8$ & $69 \pm 7$ & 0.44 \\
\hline Heterogeneity index ${ }^{\pi}$ & $19 \pm 12$ & $21 \pm 11$ & 0.60 \\
\hline GOLD stage IV & 55 & 50 & $>0.99$ ๆา \\
\hline $\mathrm{FEV}_{1} \mathrm{~L}$ & $0.79 \pm 0.22$ & $0.83 \pm 0.25$ & 0.69 \\
\hline FEV $_{1} \%$ pred & $32 \pm 8$ & $33 \pm 8$ & 0.61 \\
\hline FRC $\%$ pred & $192 \pm 19$ & $211 \pm 39$ & 0.07 \\
\hline TLC \% pred & $128 \pm 12$ & $140 \pm 21$ & 0.04 \\
\hline RV \% pred & $222 \pm 31$ & $235 \pm 51$ & 0.35 \\
\hline 6MWD m & $356 \pm 74$ & $380 \pm 58$ & 0.27 \\
\hline SGRQ total score ${ }^{+}$ & $61 \pm 12$ & $63 \pm 16$ & 0.70 \\
\hline mMRC dyspnoea score ${ }^{f}$ & $3 \pm 0.6$ & $3 \pm 0.7$ & $0.43^{++}$ \\
\hline BODE index score ${ }^{\# \#}$ & $5 \pm 1$ & $5 \pm 1$ & $0.32^{++}$ \\
\hline
\end{tabular}

Data are presented as mean \pm SD or $\%$, unless otherwise stated. BMI: body mass index; GOLD: Global Initiative for Chronic Obstructive Lung Disease; FEV 1 : forced expiratory volume in $1 \mathrm{~s}$; FRC: functional residual capacity; TLC: total lung capacity; RV: residual volume; 6MWD: 6-min walk distance; SGRQ: St George's Respiratory Questionnaire; mMRC: modified Medical Research Council; BODE: BMI, airflow obstruction, dyspnoea, exercise capacity. \#: emphysema destruction score of the target lobe was assessed as the percentage of voxels <-910 $\mathrm{HU}$ on computed tomography; ๆ: difference in emphysema score between the target lobe and the ipsilateral lobe; ${ }^{+}$: score range from 0 to 100 , with lower score indicating better quality of life; ${ }^{f}$ : scale ranges from 0 to 4, with higher scores indicating more severe symptoms of dyspnoea; ${ }^{\# \#}$ : score ranges from 0 to 10 , with higher scores indicating larger mortality risk. p-values obtained by two-sample t-test, unless otherwise stated. ${ }^{\text {กा: }}$ Fisher's exact test; ${ }^{++}$: Wilcoxon rank sum test.

\section{Secondary outcomes}

Average changes in key secondary outcome measures from baseline through 3 and 6 months of the ELVR group compared to the no-ELVR group are demonstrated in figure 3 and supplementary figures S1 and S2. At 6-month follow-up, all secondary outcome measures met statistical between-group significance in ITT analysis: increased $\mathrm{FEV}_{1}(+0.21 \mathrm{~L}, 95 \% \mathrm{CI} 0.11-0.30 \mathrm{~L} ; \mathrm{p}<0.001)$ and $6 \mathrm{MWD}(+58 \mathrm{~m}, 95 \%$ CI $24-93 \mathrm{~m}$; $\mathrm{p}<0.01)$ and reduced RV $(-0.95 \mathrm{~L}, 95 \%$ CI $-1.37--0.53 \mathrm{~L} ; \mathrm{p}<0.001)$, SGRQ total score $(-18$ points, $95 \%$

TABLE 2 Treatment-related adverse events and in-hospital stay during 6 months' follow-up

\begin{tabular}{|c|c|c|c|}
\hline & ELVR & No-ELVR & LVRS \\
\hline Subjects & 20 & 18 & 16 \\
\hline \multicolumn{4}{|l|}{ Adverse event } \\
\hline Pneumothorax & $2(10)$ & $0(0)$ & $1(6)$ \\
\hline Heimlich valve & 0 & NA & $4(25)$ \\
\hline Event requiring bronchoscopy ${ }^{\#}$ & 7 (35) & $0(0)$ & $2(13)$ \\
\hline Moderate respiratory event & $12(60)$ & $12(67)$ & $3(19)$ \\
\hline Severe respiratory event ${ }^{+}$ & $9(45)$ & $5(28)$ & $13(81)$ \\
\hline Death & $0(0)$ & $1(6)$ & $1(6)$ \\
\hline \multicolumn{4}{|l|}{ In-hospital stay days } \\
\hline For intervention & $5(5-55)$ & NA & $14.5(7-61)$ \\
\hline During follow-up $\S$ & $10(6-14)$ & $16(10-33)$ & $7.5(2-77)$ \\
\hline \multicolumn{4}{|c|}{$\begin{array}{l}\text { Data are presented as } n, n(\%) \text { or median (range). ELVR: endoscopic lung volume reduction; NA: not } \\
\text { applicable. \#: endobronchial valves removal (pneumothorax; no treatment benefit; valve dislocation), } \\
\text { symptomatic bronchial impaction; " ": event with need for medication, but no hospitalisation required (acute } \\
\text { exacerbation of COPD, any lower respiratory tract infection); }{ }^{+} \text {: event with need for repeat bronchoscopy, } \\
\text { prolonged hospitalisation with chest tube (due to pneumothorax, post-operative pulmonary air leak or } \\
\text { subcutaneous emphysema) or medication and hospitalisation required (due to acute exacerbation of COPD, } \\
\text { any lower respiratory tract infection, acute pulmonary embolism); }{ }^{\S}: \text { ELVR } n=6(30 \%) \text {, no-ELVR } n=5(28 \%) \text {, } \\
\text { LVRS } n=4(25 \%) \text { hospitalised during } 6 \text { months' follow-up. }\end{array}$} \\
\hline
\end{tabular}




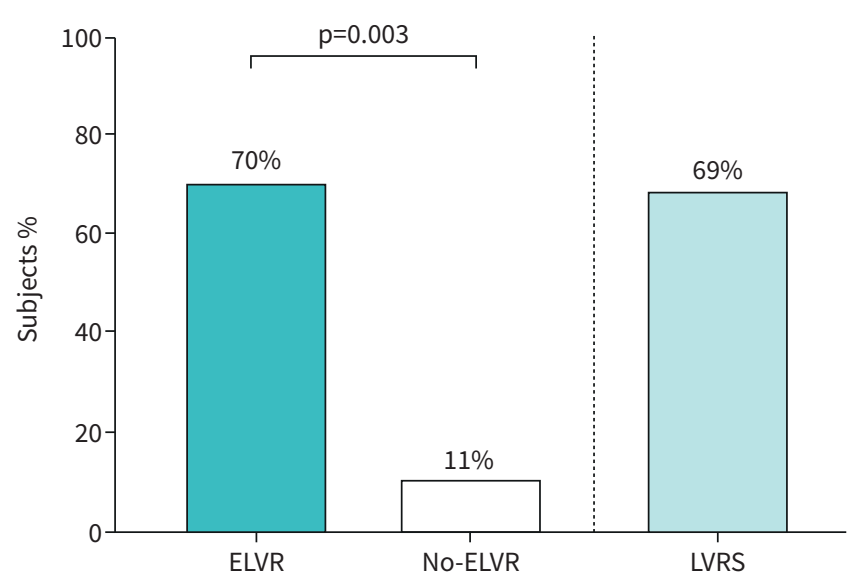

FIGURE 2 Primary end-point: percentage of subjects achieving a $\geqslant 100 \mathrm{~mL}$ improvement in post-bronchodilator forced expiratory volume in $1 \mathrm{~s}$ in the intention-to-treat population at 3 months. p-value obtained by Fisher's exact test. ELVR: endoscopic lung volume reduction; LVRS: lung volume reduction surgery.

CI $-28--7$ points; $\mathrm{p}<0.001)$ and BODE index score $(-1.6$ points, $95 \% \mathrm{CI}-2.3--0.8$ points; $\mathrm{p}<0.001)$ for ELVR compared to no-ELVR (table 3 and supplementary table S1). A significantly greater proportion of subjects in the ELVR group compared to the no-ELVR group met or exceeded the MCID for FEV 1
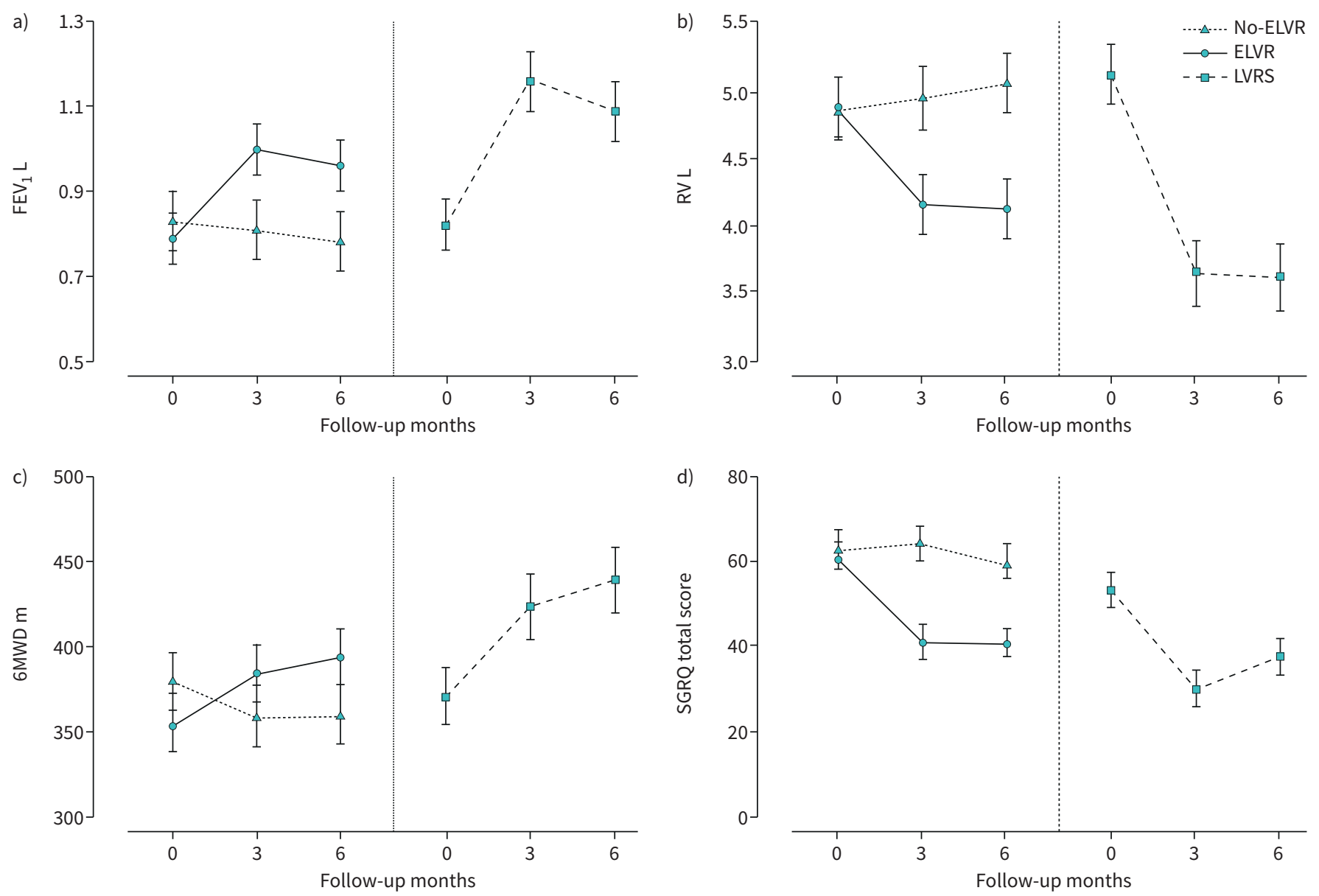

FIGURE 3 Absolute changes from baseline in key outcome measures at 3 and 6 months post-allocation to endoscopic lung volume reduction (ELVR) group, no-ELVR group and lung volume reduction surgery (LVRS) group. Data presented are mean \pm SEM for a) forced expiratory volume in $1 \mathrm{~s}\left(\mathrm{FEV}_{1}\right)$, b) residual volume (RV), c) 6-min walk distance (6MWD) and d) St George's Respiratory Questionnaire (SGRQ) total score. 


\begin{tabular}{|c|c|c|c|c|}
\hline & $\begin{array}{c}\Delta \text { ELVR versus no-ELVR at } \\
\text { 3-month follow-up }\end{array}$ & p-value & $\begin{array}{c}\Delta \text { ELVR versus no-ELVR at } \\
\text { 6-month follow-up }\end{array}$ & p-value \\
\hline $\mathrm{FEV}_{1} \mathrm{~L}$ & $0.22 \pm 0.05$ & $<0.001$ & $0.21 \pm 0.05$ & $<0.001$ \\
\hline RV L & $-0.81 \pm 0.22$ & $<0.001$ & $-0.95 \pm 0.21$ & $<0.001$ \\
\hline FRC L & $-0.55 \pm 0.17$ & 0.002 & $-0.59 \pm 0.17$ & $<0.001$ \\
\hline TLC L & $-0.40 \pm 0.14$ & 0.005 & $-0.39 \pm 0.14$ & 0.007 \\
\hline 6MWD m & $51 \pm 18$ & 0.005 & $58 \pm 17$ & 0.001 \\
\hline SGRQ total score & $-22 \pm 5$ & $<0.001$ & $-18 \pm 5$ & 0.001 \\
\hline $\begin{array}{l}\text { BODE index } \\
\text { score }\end{array}$ & $-2.7 \pm 0.4$ & $<0.001$ & $-1.6 \pm 0.4$ & $<0.001$ \\
\hline $\begin{array}{l}\text { mMRC dyspnoea } \\
\text { score }\end{array}$ & $-1.4 \pm 0.3$ & $<0.0001$ & $-0.7 \pm 0.3$ & 0.008 \\
\hline
\end{tabular}

Data are presented as mean \pm SEM (ANCOVA with baseline as covariate). Analyses at 3 months are based on 16 subjects in the no-endoscopic lung volume reduction (no-ELVR) group and 20 subjects in the ELVR group, and at 6 months on 17 subjects in the no-ELVR group and 20 subjects in the ELVR group. FEV ${ }_{1}$ : forced expiratory volume in $1 \mathrm{~s}$; RV: residual volume; FRC: functional residual capacity; TLC: total lung capacity; 6MWD: 6-min walk distance; SGRQ: St George's Respiratory Questionnaire; BODE: body mass index, airflow obstruction, dyspnoea, exercise capacity; mMRC: modified Medical Research Council.

(change of $\geqslant 100 \mathrm{~mL}$ ), RV (change of $\leqslant-430 \mathrm{~mL}$ ), 6MWD (change of $\geqslant 30 \mathrm{~m}$ ) and SGRQ (change of $\leqslant-7$ points), indicating meaningful clinical benefit was achieved at 3 - and 6-month follow-up (table 4).

\section{Exploratory analysis}

The LVRS group showed similar improvements in key secondary outcome measures from baseline to 3 and 6 months as compared to the ELVR group (figure 3 and supplementary figures S1 and S2). Within-group differences for changes at 6-month follow-up for $\mathrm{FEV}_{1}, \mathrm{RV}, 6 \mathrm{MWD}$ and BODE index and SGRQ total score were in the same range as the observed differences for ELVR (table 5). Responder rates of LVRS on established MCID was 63\% for $\mathrm{FEV}_{1}, 69 \%$ for RV, 56\% for 6MWD and 63\% for SGRQ at 6-month follow-up. Exploratory comparison between ELVR and LVRS is presented in supplementary tables S2 and S4).

\section{Adverse events}

Treatment-related adverse events and in-hospital stay during 6 months' follow-up are listed in table 2. A median in-hospital stay of 5 versus 15 days $(\mathrm{p}<0.001)$ was observed for ELVR compared to LVRS. Since discharge from the LVR intervention we observed no significant difference $(p=0.69)$ for in-hospital stay between the ELVR and LVRS groups during 6 months' follow-up. Subjects in the ELVR group experienced significantly more moderate respiratory adverse events (60\% versus $19 \%$; $=0.02)$, but significantly fewer treatment-related serious adverse events ( $45 \%$ versus $81 \%$; $=0.04)$ compared to subjects in the LVRS group.

TABLE 4 Percentage of minimum clinically important difference responders for key outcome measures for the endoscopic lung volume reduction (ELVR) and no-ELVR groups at 3-and 6-month follow-up

\begin{tabular}{|c|c|c|c|c|c|c|}
\hline & $\begin{array}{l}\text { ELVR 3-month } \\
\text { follow-up }\end{array}$ & $\begin{array}{l}\text { No-ELVR 3-month } \\
\text { follow-up }\end{array}$ & $\mathrm{p}$-value & $\begin{array}{l}\text { ELVR 6-month } \\
\text { follow-up }\end{array}$ & $\begin{array}{l}\text { No-ELVR 6-month } \\
\text { follow-up }\end{array}$ & $p$-value \\
\hline $\mathrm{FEV}_{1} \geqslant+100 \mathrm{~mL}$ & 70 & 11 & $<0.001$ & 45 & 11 & 0.03 \\
\hline $6 M W D \geqslant+30 m$ & 50 & 6 & 0.004 & 55 & 6 & 0.001 \\
\hline SGRQ $\leqslant-4$ points & 70 & 28 & 0.02 & 85 & 39 & 0.006 \\
\hline$S G R Q \leqslant-7$ points & 60 & 22 & 0.03 & 80 & 33 & 0.008 \\
\hline
\end{tabular}

Data are presented as \%, unless otherwise stated. $\mathrm{FEV}_{1}$ : forced expiratory volume in $1 \mathrm{~s}$; RV: residual volume; 6MWD: 6-min walk distance; SGRQ: St George's Respiratory Questionnaire. p-values obtained by Fisher's exact test. 


\begin{tabular}{|c|c|c|c|c|}
\hline & \multicolumn{2}{|c|}{ LVRS } & \multirow[t]{2}{*}{$\Delta$ LVRS 6-month follow-up } & \multirow[t]{2}{*}{ p-value } \\
\hline & Baseline & 6 months & & \\
\hline Subjects & 16 & 14 & & \\
\hline $\mathrm{FEV}_{1} \mathrm{~L}$ & $0.78 \pm 0.07$ & $1.05 \pm 0.07$ & $0.27 \pm 0.06$ & 0.0001 \\
\hline RV L & $5.37 \pm 0.26$ & $3.88 \pm 0.27$ & $-1.49 \pm 0.22$ & $<0.0001$ \\
\hline RV \% pred & $256 \pm 11$ & $186 \pm 12$ & $-70 \pm 10$ & $<0.0001$ \\
\hline FRC L & $6.62 \pm 0.30$ & $5.37 \pm 0.32$ & $-1.25 \pm 0.24$ & $<0.0001$ \\
\hline TLC L & $8.01 \pm 0.33$ & $7.00 \pm 0.35$ & $-1.01 \pm 0.25$ & 0.0005 \\
\hline 6MWD m & $365 \pm 17$ & $439 \pm 18$ & $75 \pm 18$ & 0.0003 \\
\hline SGRQ total score & $56 \pm 4$ & $38 \pm 4$ & $-18 \pm 4$ & $<0.0001$ \\
\hline BODE index score & $5 \pm 0.4$ & $2.9 \pm 0.4$ & $-2 \pm 0.4$ & $<0.0001$ \\
\hline mMRC dyspnoea score & $2.7 \pm 0.2$ & $1.2 \pm 0.2$ & $-1.5 \pm 0.3$ & $<0.0001$ \\
\hline
\end{tabular}

Data are presented as $\mathrm{n}$ or mean \pm SEM, unless otherwise stated. $\mathrm{FEV}_{1}$ : forced expiratory volume in $1 \mathrm{~s}$; RV: residual volume; FRC: functional residual capacity; TLC: total lung capacity; 6MWD: 6-min walk distance; SGRQ: St George's Respiratory Questionnaire; BODE: body mass index, airflow obstruction, dyspnoea, exercise capacity; mMRC: modified Medical Research Council.

\section{Discussion}

This prospective study demonstrates that the adoption of a MEET and a strategy to consider ELVR or LVRS based on Chartis assessment results in a clinical meaningful improvement of $\mathrm{FEV}_{1}, \mathrm{RV}$, symptoms of dyspnoea, exercise capacity and quality of life in patients with severe emphysema and hyperinflation. The study met its primary end-point at 3 months' follow-up with $70 \%$ of ELVR subjects compared with $11 \%$ of no-ELVR subjects achieving an improvement in $\mathrm{FEV}_{1} \geqslant 100 \mathrm{~mL}(\mathrm{p}<0.001)$; the absolute between-group difference of $+220 \mathrm{~mL}$ for $\mathrm{FEV}_{1}$ at 3 months signifies a meaningful important clinical change [16]. LVRS resulted in $69 \%$ of subjects achieving an improvement in $\mathrm{FEV}_{1} \geqslant 100 \mathrm{~mL}$ at 3 -month follow-up.

While randomised clinical trials comparing ELVR with standard of care have reported similar results, we are the first to show prospectively how the implementation of a MEET in real-life clinical practice assists in the development of a successful programme resulting in a holistic consideration and tailored intervention for each subject with advanced emphysema. More than half (61 (58\%) out of 106) of the patients evaluated at the initial MEET discussion underwent either lung transplantation or a lung volume reduction intervention. More than $90 \%$ (35 (92\%) out of 38) of the subjects entering the study underwent a tailored lung volume reduction intervention. The relationship between the degree of RV reduction and magnitude of clinical benefit suggests that both ELVR by EBVs and LVRS could be considered depending on the collateral ventilation status, the target zones for LVR, risk factors and patient preferences. ELVR by EBVs has an advantage of reversibility in case of absence of clinical benefit, with LVRS or lung transplantation in some patients as alternative treatment options.

Although neither designed nor powered to compare ELVR to LVRS, we performed an exploratory analysis (supplementary table S2). Between-group differences for changes from baseline (mean \pm SEM) seem clinically in favour of LVRS for RV $(-0.75 \pm 0.27 \mathrm{~L}), \mathrm{FEV}_{1}(0.09 \pm 0.07 \mathrm{~L}), 6 \mathrm{MWD}(32 \pm 22 \mathrm{~m})$ and BODE index ( $-0.6 \pm 0.5$ points) compared to ELVR at 6-month follow-up. No between-group difference for changes in SGRQ total score at 6-month follow-up were observed despite a numerical superiority for lung function and exercise capacity. A significant longer median in-hospital stay of 15 days was observed for LVRS compared to 5 days for ELVR. Finally, significantly ( $p=0.04)$ more LVRS subjects $(81 \%)$ compared to ELVR subjects (45\%) experienced a serious adverse events during this 6-month follow-up period. The main treatment related serious adverse events of LVRS were a prolonged ( $>10$ days) in-hospital stay in $69 \%$ of subjects, and a prolonged (>10 days) pulmonary air leak in $56 \%$ of subjects. The main treatment-related serious adverse event of ELVR was a repeat bronchoscopy in 35\% and a pneumothorax in $10 \%$ of the subjects. The observed frequency of pneumothorax in our study is 2.5 times lower than reported in a previous randomised controlled study, which might be explained by bedrest and cough suppression during the first $48 \mathrm{~h}$, and an in-hospital stay with reduced activities for 5 days [15]. The frequency of repeat bronchoscopy was similar to the STELVIO trial [7]. During the 6-month follow-up period there were significantly fewer $(\mathrm{p}=0.02)$ moderate respiratory adverse events reported in the LVRS group compared to the ELVR group, due to more acute exacerbations requiring a medical intervention in the latter. 
A reduction of $>1$ point in BODE index score has been associated with a significant decrease in mortality [21]. Randomised controlled trials confirmed the clinically significant benefit of a lung volume reduction intervention at 1-year follow-up either by $\operatorname{LVRS}$ or by $\operatorname{ELVR}[5,7,10]$. In our study, stable BODE index scores were observed in the no-ELVR control population, while both ELVR and LVRS interventions resulted in clinically relevant improvements in BODE index score at 3 and 6 months. The observed improvements in BODE score are related to a direct effect of $L V R$ on $\mathrm{FEV}_{1}$, and may also be attributed to changes in multidimensional outcomes such as walk distance, quality of life and BMI. Since we implemented a physical activity coaching intervention from 3 to 6 months in all treatment groups to maximise the clinical benefit of ELVR and to optimise functional status prior to LVRS, the impact of this coaching programme on improved BODE index score cannot be excluded.

The present study has certain limitations, as there is inevitable bias with the pragmatic study design in which allocation to early ELVR or postponed LVRS was not randomised. First, LVRS was delayed by 6 months after study inclusion in order to have a control group without ELVR while allowing LVR intervention for all subjects. However, three (17\%) subjects initially allocated to the control group due to the presence of collateral ventilation did not undergo LVRS at 6-month follow-up as one patient died and two were referred for lung transplantation. Clinical deterioration and selective dropout can occur during a control period, affecting the exploratory comparison between both LVR interventions. Second, the short follow-up period of 6 months reports only on the magnitude of direct clinical benefit from the interventions, while its impact on the long-term and potential effect on the natural evolution of the disease remains largely unknown. So far, LVR studies reported a gradual decline over time for mechanical lung function parameters, probably due to COPD progression, while patient-related outcomes (dyspnoea score) demonstrated a sustained improvement at 3 years and 5 years, respectively [5, 22]. Third, the large improvements noted in SGRQ scores could have been influenced by the open-label design. However, improvements in quality of life for subjects who underwent LVRS at 6 months were similar to those of the ELVR group, while patients in no-ELVR group did not deteriorate. Finally, although exploratory in nature, observed differences in efficacy and treatment-related serious adverse events between ELVR and LVRS may be related to the unilateral versus simultaneous bilateral intervention, respectively. In addition, we considered LVRS only for patients with collateral ventilation and who were fit enough for surgery. A randomised direct comparison of unilateral LVRS and ELVR in collateral ventilation negative patients is therefore still warranted.

In conclusion, LVR provides both clinically meaningful benefits in lung function, exercise tolerance and quality of life with less morbidity for ELVR in appropriately selected patients after a MEET discussion. This pragmatic prospective cohort study supports a clinical approach with ELVR as a less-invasive first option in patients with severe heterogeneous emphysema and LVRS as a powerful alternative for those who are not candidates for ELVR or who did not respond to ELVR.

Acknowledgements: The authors thank Karen Denaux, Maylorie 't Lam and Kaat Haesendonck (University Hospitals KU Leuven, Leuven, Belgium) for their indispensable support in the organisation of the study and the data collection. David Ruttens and Nina Cardinaels (University Hospitals KU Leuven) are acknowledged for the optimal clinical care of all study patients. We are grateful to all patients and relatives for their participation in the study.

Conflict of interest: C. Dooms has nothing to disclose. A. Blondeel has nothing to disclose. L.J. Ceulemans has nothing to disclose. J. Coolen has nothing to disclose. S. Everaerts has nothing to disclose. H. Demeyer has nothing to disclose. T. Troosters has nothing to disclose. G. Verleden has nothing to disclose. D. Van Raemdonck has nothing to disclose. W. Janssens reports grants from PulmonX (for the endobronchial valves). He receives grants from AstraZeneca and Chiesi, outside the submitted work. W. Janssens is co-founder of ArtiQ, a KU Leuven spin-off company in respiratory diseases.

Support statement: Wim Janssens is senior Clinical Investigator of the Flemish Research Funds. Heleen Demeyer is a post-doctoral research fellow of the Flemish Research Foundation (FWO Flanders). Astrid Blondeel is a pre-doctoral research fellow of FWO Flanders (1194320N). Thierry Troosters is supported by FWO Flanders (grant number FWO G 0C0720N). This study was supported by PulmonX Corporation, RMS Medical Devices, Chiesi Belgium and clinical research funding from University Hospitals Leuven. Funding information for this article has been deposited with the Crossref Funder Registry.

\section{References}

1 Decramer M, Janssens W, Miravitlles M. Chronic obstructive pulmonary disease. Lancet 2012; 379: 1341-1351.

2 Vestbo J, Hurd SS, Agustí AG, et al. Global strategy for the diagnosis, management, and prevention of chronic obstructive pulmonary disease: GOLD executive summary. Am J Respir Crit Care Med 2013; 187: 347-365.

3 Fishman A, Martinez F, Naunheim K, et al. A randomised trial comparing lung-volume-reduction surgery with medical therapy for severe emphysema. N Engl J Med 2003; 348: 2059-2073.

4 Naunheim KS, Wood DE, Mohsenifar Z, et al. Long-term follow-up of patients receiving lung-volume-reduction surgery versus medical therapy for severe emphysema by the National Emphysema Treatment Trial Research Group. Ann Thorac Surg 2006; 82: 431-443. 
5 Lim E, Sousa I, Shah PL, et al. Lung volume reduction surgery: reinterpreted with longitudinal data analyses methodology. Ann Thorac Surg 2020; 109: 1496-1501.

6 Sciurba FC, Ernst A, Herth FJF, et al. A randomised study of endobronchial valves for advanced emphysema. N Engl J Med 2010; 363: 1233-1244.

7 Klooster K, ten Hacken NH, Hartman JE, et al. Endobronchial valves for emphysema without interlobar collateral ventilation. N Engl J Med 2015; 373: 2325-2335.

8 Davey C, Zoumot Z, Jordan S, et al. Bronchoscopic lung volume reduction with endobronchial valves for patients with heterogeneous emphysema and intact interlobar fissures (the BeLieVeR-HIFi study): a randomised controlled trial. Lancet 2015; 386: 1066-1073.

9 Kemp SV, Slebos DJ, Kirk A, et al. A multicenter randomised controlled trial of Zephyr endobronchial valve treatment in heterogeneous emphysema (TRANSFORM). Am J Respir Crit Care Med 2017; 196: 1535-1543.

10 Criner GJ, Sue R, Wright S, et al. A multicenter randomised controlled trial of Zephyr endobronchial valve treatment in heterogeneous emphysema (LIBERATE). Am J Respir Crit Care Med 2018; 198: 1151-1164.

11 Hartman JE, Klooster K, Slebos DJ. From bench to bedside: implementation of endobronchial valve treatment for patients with advanced emphysema in routine clinical care. Respiration 2020; 99: 187-188.

12 Gordon M, Duffy S, Criner GJ. Lung volume reduction surgery or bronchoscopic lung volume reduction: is there an algorithm for allocation? J Thorac Dis 2018; 10: Suppl. 23: S2816-S2823.

13 Eichhorn ME, Gompelmann D, Hoffmann H, et al. Consolidating lung volume reduction surgery after endoscopic lung volume reduction failure. Ann Thorac Surg 2020; in press [https://doi.org/10.1016/j.athoracsur.2020.06.148].

14 Slebos DJ, Shah PL, Herth FJ, et al. Endobronchial valves for endoscopic lung volume reduction: best practice recommendations from expert panel on endoscopic lung volume reduction. Respiration 2017; 93: 138-150.

15 Herzog D, Thomsen C, Poellinger A, et al. Outcomes of endobronchial valve treatment based on the precise criteria of an endobronchial catheter for detection of collateral ventilation under spontaneous breathing. Respiration 2016; 91: 69-78.

16 Donohue JF. Minimal clinically important differences in COPD lung function. COPD 2005; 2: 111-124

17 Hartman JE, Ten Hacken NH, Klooster K, et al. The minimal important difference for residual volume in patients with severe emphysema. Eur Respir J 2012; 40: 1137-1141.

18 Jones PW. St. George's Respiratory Questionnaire: MCID. COPD 2005; 2: 75-79.

19 Welling JB, Hartman JE, Ten Hacken NH, et al. The minimal important difference for the St George's Respiratory Questionnaire in patients with severe COPD. Eur Respir J 2015; 46: 1598-1604.

20 Singh SJ, Puhan MA, Andrianopoulos V, et al. An official systematic review of the European Respiratory Society/ American Thoracic Society: measurement properties of field walking tests in chronic respiratory disease. Eur Respir J 2014; 44: 1447-1478.

21 Martinez FJ, Han MK, Andrei AC, et al. Longitudinal change in the BODE index predicts mortality in severe emphysema. Am J Respir Crit Care Med 2008; 178: 491-499.

22 Gompelmann D, Heinhold T, Rötting M, et al. Long-term follow up after endoscopic valve therapy in patients with severe emphysema. Ther Adv Respir Dis 2019; 13: 1753466619866101. 